\title{
Leukocyte Depletion by Therapeutic Leukocytapheresis in Patients with Leukemia
}

\author{
Kristina Hölig ${ }^{a}$ Rainer Moog ${ }^{b, c}$ \\ ${ }^{a}$ Department of Internal Medicine I, University Hospital Carl Gustav Carus, TU-Dresden \\ ${ }^{\mathrm{b}}$ Hospital Laboratory Network Brandenburg-Berlin, \\ c plusBlut, Hennigsdorf, Germany
}

\section{Keywords}

Hyperleukocytosis - Leukostasis .

Therapeutic leukocytapheresis · Acute leukemia

\section{Summary}

Hyperleukocytosis is a complication of various leukemias and can result in life-threatening leukostasis. Critical white blood cell (WBC) counts are conventionally defined as higher than $100 \times 10^{9} / \mathrm{I}$ in acute myeloid leukemia and $>300 \times 10^{9} / \mathrm{l}$ in acute lymphatic leukemia and other leukemic disorders (e. g. chronic myeloid leukemia). Leukocytapheresis is a therapeutic tool to reduce leukocyte counts in patients with symptomatic or threatening leukostasis until induction chemotherapy works. In patients with temporary contraindications against cytotoxic drugs, e.g. during pregnancy, leukocytapheresis can be used as a bridging therapy until conventional chemotherapy can be started. Therapeutic leukocytapheresis should be performed in specialized centers by experienced, well-trained staff. Thorough monitoring of the patients is extremely relevant. During a single procedure, WBC count can be reduced by 10-70\%. Treatment should be repeated daily and can be discontinued when the symptoms of leukostasis have been resolved and/or leukocyte counts have fallen below the critical thresholds. There are no prospective studies evaluating the clinical efficacy of therapeutic leukocytapheresis in patients with hyperleukocytosis. It can be concluded from retrospective studies that leukocytapheresis might have some beneficial effect in early morbidity and mortality of patients with newly diagnosed AML but has no influence on overall long-term survival. Induction chemotherapy is the most important treatment in these patients and must never be postponed.

\author{
Schlüsselwörter \\ Hyperleukozytose · Leukostase . \\ Therapeutische Leukozytapherese · Akute Leukämie
}

\section{Zusammenfassung}

Leukozytose ist eine Komplikation verschiedener Leukämien und kann zur lebensbedrohlichen Leukostase führen. Als kritische Leukozytenzahlen gelten im Allgemeinen Werte über $100 \times 10^{9} / \mathrm{l}$ bei akuten myeloischen Leukämien und über $300 \times 10^{9} / \mathrm{l}$ bei akuter lymphatischer Leukämie und anderen Leukämieformen (z. B. chronisch-myeloische Leukämie). Mittels therapeutischer Leukozytapherese können pathologisch erhöhte Leukozytenwerte bei Patienten mit symptomatischer oder drohender Leukostase reduziert werden, bis die Wirkung der Induktions-Chemotherapie einsetzt. Bei Patienten mit vorübergehenden Kontraindikationen gegen Zytostatika, wie z.B. in der Schwangerschaft, dient die Leukozytapherese zur Überbrückung des Zeitraums, bis die konventionelle Chemotherapie begonnen werden kann. Leukozytapheresen sollten nur in spezialisierten Zentren von erfahrenem, geschultem Personal durchgeführt werden. Eine sorgfältige Überwachung der Patienten ist von besonderer Bedeutung. Während einer Behandlung kann die Leukozytenzahl um 10-70\% reduziert werden. Die Behandlung sollte täglich wiederholt werden, bis die Leukostasesymptomatik abgeklungen bzw. die Leukozytenzahl unter die kritische Interventionsschwelle abgefallen ist. Es mangelt an prospektiven, randomisierten, kontrollierten Studien, die den klinischen Effekt der therapeutischen Leukozytapherese bei Patienten mit Leukostase evaluieren. Retrospektive Studien lassen auf eine therapeutische Wirksamkeit der Leukozytapherese hinsichtlich Frühmorbidität und -mortalität bei Patienten mit neu diagnostizierter AML schließen. Ein Einfluss dieser Therapie auf das Gesamtüberleben von AML-Patienten konnte nicht nachgewiesen werden. Die entscheidende Therapie für diese Patienten ist die Induktions-Chemotherapie, die deshalb auch keinesfalls verzögert werden sollte.

\section{KARGER \\ Fax +497614520714 \\ Information@Karger.de}

www.karger.com
(C) 2012 S. Karger GmbH, Freiburg

$1660-3796 / 12 / 0394-0241 \$ 38.00 / 0$

Accessible online at:

www.karger.com/tmh
Dr. Kristina Hölig

Department of Internal Medicine I

University Hospital Carl Gustav Carus, TU-Dresden

Fetscherstraße 74, 01307 Dresden, Germany

kristina.hoelig@uniklinikum-dresden.de 


\section{Introduction}

Therapeutic leukocytapheresis is a symptomatical treatment of hyperleukocytosis in acute and chronic leukemias. The objective of this procedure is to reduce highly elevated WBC counts in order to prevent or to treat leukostatic syndrome. Leukostasis is regarded as a major prognostic factor for early mortality in acute leukemias [1]. Leukocytes and especially leukemic blasts are less deformable than red cells. A massive elevation of this cell population is associated with an increase of blood viscosity [2]. This can give rise to occlusion of blood vessels with ischemia, hypoxia, and endothelial damage. Another aspect of the pathogenesis may be the activation of endothelial cells by blast secreted cytokines (TNF- $\alpha$ and IL-1 $\beta$ ) and interactions between leukemic and endothelial cells by adhesion molecules (e.g. selectins and VCAM-1). Both mechanisms might as well act synergistically to promote the leukostatic syndrome [3].

Tissue hemorrhage and loss of organ functions are secondary consequences of these pathologic events. Furthermore, there is an increasing risk of leukemic infiltration in the organs involved.

Typical organ manifestations of leukostasis are the lung vasculature and the central nervous system (CNS). The clinical symptoms of leukostasis are specified in table 1 .

Embolism of periphery arteries with ischemic lesion of corresponding extremities is reported in some clinical cases [4]. Priapism in male patients due to leukostasis represents a special emergency situation. Novotny et al. [5] proposed a risk score for the probability of leukostasis in patients with leukemia and hyperleukocytosis. They divided their patients into four groups - none, possible, probable, and highly probable

Table 1. Symptoms of leukostasis

\begin{tabular}{ll}
\hline Organ & Symptoms \\
\hline Lung & $\begin{array}{l}\text { dyspnea, hypoxemia, diffuse alveolar } \\
\text { hemorrhage, respiratory failure } \\
\text { Central nervous system }\end{array}$ \\
& $\begin{array}{l}\text { confusion, somnolence, dizziness, headache, } \\
\text { delirium, coma, focal neurological deficits }\end{array}$ \\
Eye & impaired vision, retinal hemorrhage \\
Ear & tinnitus \\
Heart & myocardial ischemia/infarction \\
Vascular system & limb ischemia, renal vein thrombosis, \\
& priapism
\end{tabular}

leukostasis. Up to now, this grading system has not yet been clinically validated but it might be an interesting tool for future studies

The critical WBC count, giving rise for therapeutic intervention, is not clearly defined. The incidence and severity of leukostatic symptoms seem to be essentially dependent on the type of leukemia. The risks seem to be particularly high in acute myeloid leukemia (AML), where WBC counts between 50 and $100 \times 10^{9} / 1$ are regarded dangerous and an indication for leukocytapheresis. Leukocyte counts $>300 \times 10^{9} / 1$ in AML patients resemble an absolute indication for leukocytapheresis. In chronic-myeloid leukemia and lymphatic leukemias, a substantial risk of leukostasis seems to arise only with WBC counts remarkable higher than $300 \times 10^{9} / 1$. Because of the low number of studies published the level of evidence of leukocyte depletion by leukocytapheresis is mostly low (IIc, see [6]). Prospective randomized trials have not yet been reported. The indications for therapeutic leukapheresis are summarized in table 2.

Leukocytapheresis is contraindicated in AML FAB M3 (APL) because of the accompanying disseminated intravascular coagulation which is characteristic for this subtype of AML [7]. There are no other absolute contraindications. Relative contraindications such as anemia, thrombocytopenia, systemic infections, and respiratory or circulatory insufficiency can be negotiated provided that adequate supportive treatment is done.

\section{Basic Principles}

Leukocytapheresis, according to the ASFA guidelines, means a procedure in which blood of the patient or the donor is passed through a medical device, which separates out WBCs (e.g. leukemic blasts or granulocytes), collects the selected cells, and returns the remainder of the patient's or the donor's blood with or without addition of replacement fluid such as colloid, human albumin, and/or crystalloid solution [6]. In modern apheresis devices (blood cell separators) WBCs and their precursors are separated from patient's blood by centrifugation. Therapeutic leukocytaphereses should only be performed in centers with a certain degree of experience in this method of blood cell separation. Apheresis units routinely collecting peripheral blood stem cells or granulocyte concentrates normally have the skills necessary to perform the procedure. Physicians and nurses trained in
Table 2. Indications for therapeutic leukocytapheresis (according to the Guidelines of the American Society for Apheresis (ASFA) [6], with addition)

\begin{tabular}{lll}
\hline Indication & Recommendation & Category \\
\hline AML, WBC $>100 \times 10^{9} / 1$ & grade IB & I (leukostasis) \\
ALL, WBC $>400 \times 10^{9} / 1$ & grade IIC & III (prophylaxis) \\
Other leukemias, WBC $>400 \times 10^{9} / 1$ with leukostasis & grade IC & not categorized by ASFA \\
Other leukemias, WBC $>400 \times 10^{9} / 1$ without leukostasis & grade IIC & not categorized by ASFA \\
\hline
\end{tabular}

Transfus Med Hemother 2012;39:241-245 
Table 3. Published reports on the efficacy of leucocytapheresis in patients with hyperleukocytosis

\begin{tabular}{|c|c|c|}
\hline Reference & Number of patients & Clinical results \\
\hline Bug et al., 2007 [12] & 53, AML, 25 treated with leukocytapheresis & $\begin{array}{l}\text { leukocytapheresis significantly reduced } 3 \text { week mortality; } \\
\text { overall survival after a follow-up of } 24 \text { months did not } \\
\text { differ significantly }\end{array}$ \\
\hline Kuo et al., 2006 [13] & $\begin{array}{l}89, \text { AML, } 42 \text { treated with leukocytapheresis, } \\
47 \text { received hydroxyurea }\end{array}$ & $\begin{array}{l}\text { identical survival rates at day } 8(\mathrm{p}=1.00) \text { and day } 28 \\
(\mathrm{p}=0.4784)\end{array}$ \\
\hline Giles et al., 2001 [14] & 146, AML/ 71 treated with leukocytapheresis & $\begin{array}{l}2 \text { week mortality was reduced }(\mathrm{p}=0.006) \text {, trend to a higher } \\
\text { rate of } \mathrm{CR}(\mathrm{p}=0.06) \text {; no impact on overall survival }\end{array}$ \\
\hline Porcu et al., 1997 [15] & $\begin{array}{l}48 \text { patients (AML or CML blast crisis) treated } \\
\text { with leukocytapheresis, no control group }\end{array}$ & $\begin{array}{l}\text { early mortality } 27 \% \text {, according to the literature, } \\
\text { no correlation of cytoreduction and survival rate }\end{array}$ \\
\hline Cuttner et. al., 1983[16] & 22 patients (AML) & $\begin{array}{l}>30 \% \text { reduction of WBC count correlated well with the } \\
\text { attainment of remission }\end{array}$ \\
\hline Thibaut et al., 2000 [17] & 53 patients, no control group & early mortality $3.7 \%$, lower than in the literature \\
\hline Lowe et al., 2005 [18] & $\begin{array}{l}178 \text { pediatric patients (ALL), } 94 \text { treated with } \\
\text { leukocytapheresis }\end{array}$ & $\begin{array}{l}\text { effective reduction of leukocyte count, but delayed initiation } \\
\text { of chemotherapy }\end{array}$ \\
\hline
\end{tabular}

intensive care medicine are needed if the patients are in bad clinical condition, what might often be the case. In these patients, monitoring of blood pressure, heart rate, ECG, and $\mathrm{O}_{2}$ saturation as well as oxygen supply are strongly recommended. Immediate transfer of the patient to an intensive care unit, if necessary, must be possible. Sometimes it can be necessary to move the apheresis equipment to an intensive care unit and perform the treatment at bedside. On the scale of things, close cooperation between Transfusion Medicine, Hematology, Pediatrics and Anesthesiology/Intensive Care Medicine is essential.

\section{Performance}

Informed consent of the patient or legal guardian has to be obtained before initiation of the treatment. If the patient is not able to agree and it is a life-threatening emergency situation, this has to be documented too. Peripheral venous access should be used for the leucocytapheresis procedure whenever possible in order to avoid delay and bleeding complications in these often thrombocytopenic patients. Impairment of cellular and plasmatic coagulation has to be considered during anticoagulation. Normally, citrate is the anticoagulant of choice, and the citrate/blood ratio should be kept as high as possible (i.e. 1:16 to 1:20). Heparin should not be applied because of its long-lasting systemic inhibitory effects on coagulation. The leukocytapheresis procedure has to be adjusted to the type of leukemia and other characteristics of the patient such as hematocrit, platelet count, and blood volume. The blood volume to process should be between 2 and 4 times the patient's blood volume. Under optimal conditions, the hematocrit of the apheresis product ranges from 3 to $5 \%$. In some forms of leukemia, it can be reasonable to increase the speed of rotation of the centrifuge to improve sedimentation of the leukemic blasts. This should always be considered, if the separation of red cells, WBCs and plasma cannot be observed correctly or if the color of the apheresis product is dark-red, indicating a high hematocrit. The use of sedimenting agents like hydroxyethyl starch (HES) is not required and disregarded by ASFA [6]. According to other apheresis treatments, patients should be asked for paresthesia due to hypocalcemia and receive calcium supplementation if necessary. In patients with poor general condition and in children, calcium and potassium levels should be monitored hourly and corrected by intravenous infusion. Furthermore, continuous measurement of oxygen saturation by pulse oximetry and noninvasive monitoring of arterial blood pressure and heart rate are recommended in these patients. General aspects of therapeutic aphereses in pediatric patients have been reported elsewhere $[8,9]$.

The volume of the leukocytapheresis product ranges from 200 to $1,000 \mathrm{ml}$, depending on the type of blood cell separator used and the patient's blood volume processed. If more than $20 \%$ of the patient's blood volume are collected, fluid replacement with colloids or human albumin is recommended. Red cell transfusion should be performed only at the end of the leucocytapheresis procedure, whenever possible, to avoid further increase of blood viscosity [10]. Complete blood count, electrolytes, and coagulation parameters should be determined at the beginning and the end of the procedure; pathological findings should be shared with the attending physicians. Therapeutical leukocytaphereses can be repeated daily until symptoms of leukostasis have disappeared or the WBC target count (in AML usually below $100 \times 10^{9} / 1$, in other leukemias below $\left.200 \times 10^{9} / 1\right)$ is reached. There is no clinical rationale to perform more than one treatment per day. In pregnant women and other patients with temporary contraindications to cytotoxic drugs, leukocytapheresis can be repeated for longer periods until chemotherapy can be started. 


\section{Clinical Results}

In patients with leukostasis a single treatment frequently causes remarkable improvement. During a single leukapheresis, the WBC count can be reduced by $10-70 \%$. The therapeutical benefit of leukocytapheresis has been investigated particularly in patients with AML and in pediatric patients with acute lymphatic leukemia (ALL) (table 3). Unfortunately there have been no prospective studies published to date. In 2 retrospective studies with a control group (Giles et al. [12], Bug et al. [14]), a beneficial effect of leukocytapheresis on early morbidity and mortality of patients with newly diagnosed AML could be detected, but the authors did not observe any influence on long-term survival. Another retrospective study comparing the management of 89 AML patients with leukocytapheresis versus hydroxyurea demonstrated equivalent survival on days 8 and 28 [13]. The study of Porcu et al. [15] did not reveal any difference in early mortality in patients treated with leukocytaperesis compared with the literature. Altogether there is very little evidence that therapeutic leukocytapheresis has a substantial impact on the outcome of adult AML patients with leukostasis. In the pediatric population, ALL often presents with hyperleukocytosis at time of diagnosis. Lowe et al. [18] retrospectively analyzed 178 children with ALL and hyperleukocytosis; 94 had been treated with therapeutical leukocytapheresis. The authors reported that leukocytapheresis decreased the leukocyte count but also delayed the initiation of chemotherapy $(p=0,013)$. In our own center, between 5 and 10 patients per year are treated with therapeutic leukapheresis. According to other reports, about $90 \%$ suffer from AML. Symptoms of leukostasis were detected in about $30 \%$ of the patients. In most cases, only one leukocytapheresis was performed. The reduction of leukocyte count ranged from 23 to $70 \%$ and did not correlate to the volume of the apheresis product. The treatment itself was well tolerated by all patients. Due to the lack of a control group, no long-term advantage of leukocyte depletion could be shown. In a group of 15 patients treated between 1997 and 2006 , early mortality was $27 \%$, corresponding with the literature.

\section{Risks and Side Effects}

All in all, besides the often critical overall condition of the patients with leukostasis, there have been no severe adverse events of leukocytapheresis published yet. Thrombocytopenia and coagulation disorders due to the underlying disease may be triggered by the cell separation procedure and the anticoagulation and should be treated adequately. Properly conducted, the treatment is well tolerated without major side effects.

\section{Discussion and Conclusions}

Although leukocytapheresis has been established about 50 years ago, its place in the therapeutical algorithm of leukemias is still uncertain. The technical aspects of the procedure are difficult to standardize because of the heterogeneity of leukemic cell populations. The infrequence of patients with hyperleukocytosis limits the possibility to acquire routine even in large centers. On the other hand, the efficacy of leukocyte reduction correlates not only with the amount of cells removed but also with growth pattern and distribution kinetics of the leukemic blasts. Both the technical aspects and the pathophysiology explain the large variation of leukocyte reduction that can be achieved in individual patients during a single treatment.

The body of evidence from the literature does not reveal a clear proof of an advantage of therapeutic leucocytapheresis compared with conventional cytoreductive treatment regarding long-term survival in any form of leukemia. These data indicate that hyperleukocytosis correlates with other poor prognostic factors, especially in AML and ALL, that cannot be modified by cytoreductive treatment [19].

On the contrary, there are patients who unequivocally benefit from the immediate leukocyte depletion, e.g. patients with priapism or coma due to leukostasis. The question which patients with asymptomatic hyperleukocytosis are at risk to develop life-threatening complications of leukostasis and would profit from leukocytapheresis remains intricate. A grading system like that proposed by Novotny et al. [5] might support therapeutic decisions in the future.

According to current knowledge, the following recommendations can be made:

- Hyperleukocytosis in acute leukemia represents an emergent situation requiring appropriate therapy without any delay.

- Early initiation of chemotherapy, hydroxyurea and supportive care are the therapeutical fundament and must be guaranteed.

- Patients with clear symptoms of leukostasis should undergo leukocytapheresis in a timely manner. The treatment has to be performed in a center with experience in leukocytapheresis and emergency equipment. Leukocytapheresis procedures should be repeated daily until leukostatic symptoms have disappeared and WBC count has reached safe values.

- In asymptomatic patients with hyperleukocytosis the decision for treatment remains at the discretion of the attending physician [11].

\section{Disclosure Statement}

The authors declared no conflict of interest. 


\section{References}

1 Blum W, Porcu P: Therapeutic apheresis in hyperleukocytosis and hyperviscosity syndrome. Semin Thromb Hemost 2007;33:350-354

2 Lichtman MA, Rowe JM: Hyperleukocytic leukemias: rheological, clinical, and therapeutic considerations. Blood 1982;60:279-283.

3 Stucki A, Rivier AS, Gikic M, et al: Endothelial cell activation by myeloblasts: molecular mechanisms of leukostasis and leukemic cekk dissemination. Blood 2001;97:2121-2129.

4 Kafetzakis A, Foundoulakis A, Ioannou CV, et al: Acute lower limb ischemia as the initial symptom of acute myeloid leukemia. Vasc Med 2007;12:199-202.

$\checkmark 5$ Novotny JR, Müller-Beißenhirtz H, Herget-Rosenthal S, et al: Grading of symptoms in hyperleukocytic leukemia: a clinical model for the role of different blast types and promyelocytes in the development of leukostasis syndrome. Eur J Haematol 2005;74:501-510.

6 Szczepiorkowski ZM, Winters JL, Bandarenko N, et al: Guidelines on the use of therapeutic apheresis in clinical practice - evidence-based approach from the Apheresis Applications Committee of the American Society for Apheresis. J Clin Apher 2010;25:83-177.

7 Vahdat L, Maslak P, Miller WH Jr, et al: Early mortality and the retinoic acid syndrome in acute promyelocytic leukemia: impact of leukocytosis, low-dose chemotherapy, PMN/RAR-alpha isoform, and CD13 expression in patients treated with all-trans retinoic acid. Blood 1997;84:3843-3849.

8 Goldstein SL: Therapeutic apheresis in children: special considerations. Semin Dial 2012;25:165-170.

9 Wong EC, Balogun RA: Therapeutic apheresis in pediatrics: technique adjustments, indications and nonindications, a plasma exchange focus. J Clin Apher 2012;27:132-137.

10 Harris AL: Leukostasis associated with blood transfusion in acute myeloid leukemia. BMJ 1978;1:1169-1171.

11 Ganzel C, Becker J, Mintz PD, et al: Hyperleukocytosis, leukostasis and leukapheresis: practice management. Blood Rev 2012;26:117-122.

12 Bug G, Anargyrou K, Tonn T, et al: Impact of leukapheresis on early death rate in adult acute myeloid leukemia presenting with hyperleukocytosis. Transfusion 2007;47:1843-1850.

13 Kuo KHM, Callum J, Brandwein J, et al: Management of hyperleukocytosis in acute myelogenous leukemia using hydroxyurea rather than leukopheresis. Blood (ASH Annual Meeting Abstracts) 2006;108:2007.

14 Giles FJ, Shen Y, Kantarijan HM, et. al: Leukapheresis reduces early mortality in patients with acute myeloid leukemia with high white cell counts but does not improve long-term survival. Leuk Lymphoma 2001;42:67-73.

15 Porcu P, Danielson CF, Orazi A:Therapeutic leukapheresis in hyperleucocytic leukemias: lack of correlation between degree of cytoreduction and early mortality rate.Br J Haematol 1997;98;433-436.

16 Cuttner J, Holland JF, Norton L, et al: Therapeutic leukapheresis for hyperleukocytosis in acute myelocytic leukemia. Med Pediatr Oncol 1983;11:76-78.

17 Thiebaut A, Thomas X, Belhabri A, et al: Impact of pre-induction therapy on treatment outcome in adult acute myelogenous leukemia presenting with hyperleukocytosis. Ann Hematol 2000;79:501-506.

18 Lowe EJ, Pui C-H, Hancock ML, et al: Early complications in children with acute lymphoblastic leukemia presenting with hyperleukocytosis. Pediatr Blood Cancer 2005;45:10-15.

19 Majhail NS, Lichtin AE: Acuta leukemia with a very high leukocyte count: confronting a medical emergency. Cleve Clin J Med 2004;71:633-637. 